\title{
The Changes of Apple's Stock Price During the Pandemic
}

\author{
Wanting $\operatorname{Sun}^{1, *}$ \\ ${ }^{1}$ WendySun, Kinglee High School, Zheng Zhou, He Nan, China, 450000 \\ *Corresponding author. Email: wendysun040718@163.com
}

\begin{abstract}
During the epidemic, the economies of various countries, including many large companies, were subject to very large fluctuations and impacts. Therefore, this article will explore the ups and downs of Apple's stock price during the epidemic. At different points in time and severity, Apple's stock price has risen and fallen. By observing the data on Yahoo, we can summarize Apple's stock price changes during this period. At the beginning of the epidemic, the global economy has been damaged, so Apple is no exception. So at the beginning of the epidemic, Apple's stock price fell sharply. But later, because Apple had a strong overall strength and a good foundation, it only took three months to solve the impact of the epidemic. Later, when the epidemic returned to a serious situation, Apple's stock price was implicated and fell slightly, but within a few weeks the stock price decline was resolved and returned to normal levels, and even steadily increased. Because Apple has been constantly launching new products, the epidemic will not have a very large impact on Apple's stock price.
\end{abstract}

Keywords: Apple, stock price, COVID-19

\section{INTRODUCTION}

As we know, the outbreak of the epidemic in 2020 has dealt a lot of blows to many countries and companies. Population decline, massive economic losses, and national unrest. The U.S. economic recession seems to be more serious than expected. The euro zone economy has experienced the largest decline in record, and the British economy has also suffered the largest decline since World War II. As an exogenous shock, the epidemic will inevitably have a direct impact on China's transportation, tourism and other industries. Similarly, as China is the main source of power to promote world growth, once the Chinese economy is affected, the world economy will inevitably be affected. Thus, in such an environment where the whole world is affected, to what extent have the industry giants that dominate the world been hit? Let's take the most familiar Apple company as an example, and analyze how much impact this devastating epidemic has brought to Apple's stocks in several aspects.

\section{BACKGROUND INFORMATION OF APPLE COMPANY}

Apple Inc. is an American multinational technology company that specializes in consumer electronics, computer software, and online services. In it's headquartered in Cupertino, California. Apple went public on December 12, 1980, and set a record of $\$ 623.5$ billion in market value in 2012. As of June 2014, Apple has become the world's largest company by market capitalization for three consecutive years. On September 30, 2013, in the Hongmeng Group's "Best Global Brand" report, Apple surpassed Coca-Cola to become the world's most valuable brand. In 2014, the Apple brand surpassed Google to become the world's most valuable brand. On August 19, 2020 local time, Apple's market value exceeded US\$2 trillion for the first time. Ranked 6th on the Fortune Global 500 list in 2021. Apple is the world's largest technology company by revenue and, since January 2021, the world's most valuable company. As of 2021, Apple is the world's fourth-largest PC vendor by unit sales, and fourthlargest smartphone manufacturer. 


\section{MACRO PERSPECTIVE}

From a macro perspective, the decline in population, the decrease in spending, and the increase in inventories have caused many industries to stagnate. This is bound to bring a huge blow on the global economy to a serious extent. The International Monetary Fund stated in the "April 2020 Global Economic Survey" that due to the new crown epidemic, the global economy is expected to shrink by $3 \%$ in 2020 , and the impact will be much more severe than the 2008-2009 financial crisis. Some experts have predicted that the impact of the epidemic crisis on economic contraction will be three times that of the financial crisis. The last global economic recession began at the end of 2007 and did not fully recover until June 2009. Most of Apple's components are produced in China, so when China is affected by the epidemic and the work is stopped, Apple's products cannot be made at the same time [3]. This will inevitably have a huge impact on Apple. According to information reported by the Wall Street Journal on March 24, 2020, Apple's stock price closed down 2.12\% on Monday, and its market value fell below US\$1 trillion to US\$981.7 billion. In this way, Apple fell out of the "trillion club" of US stocks, of which only Microsoft was left [7].

\section{MICRO PERSPECTIVE}

It is obvious that Apple has been affected by the epidemic in a great extent, however, we still need to take a look Apple's economic changes in a micro perspective. At the beginning of the epidemic, which is the start of February, the price started to decline. On February 3, 2020, the opening price is 76.07; the closing price is 80.01 . From this point, the closing price started to diminish. On March 23, 2020, the opening price is 57.02 , and the closing price is 56.09 . The stock price for this day is the lowest price during epidemic in Apple. Then, it started to increase gradually until September 1, this day is also a peak, the opening price on September 1 is 132.76 and the closing price is 134.18. However, after September 1, the price started to drop again. There is a very low price on September 18, 2020. The opening price is 110.40 , the closing price is 106.84 .

Apple Inc. (AAPL)

A Add to watchlist 8 Visitors trend $2 W \downarrow 10 W \uparrow 9 M \uparrow$

146.92

$+0.09(+0.06 \%)$

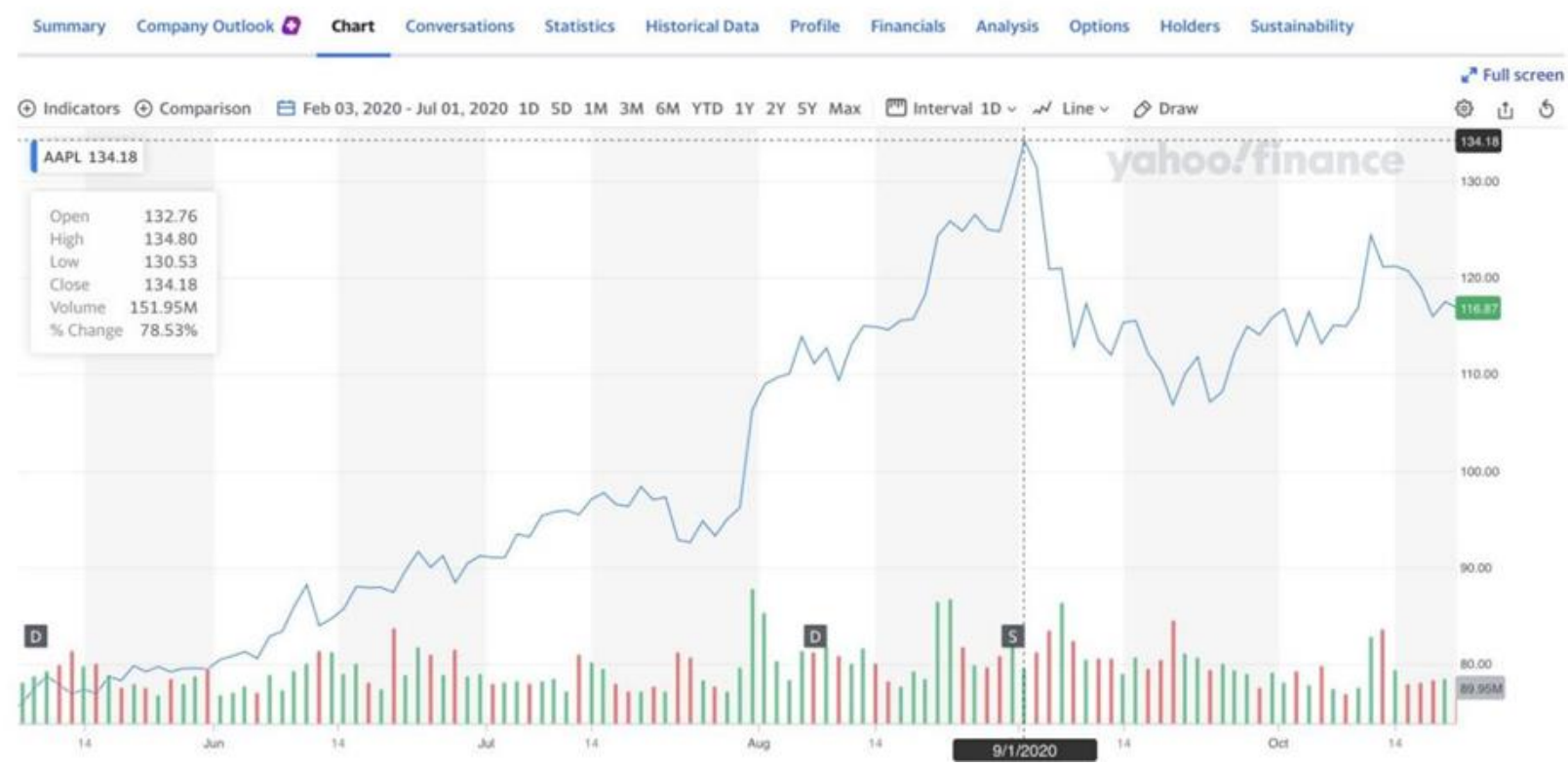

Figure 1 Apple's stock price 
$146.92+0.09(+0.06 \%)$

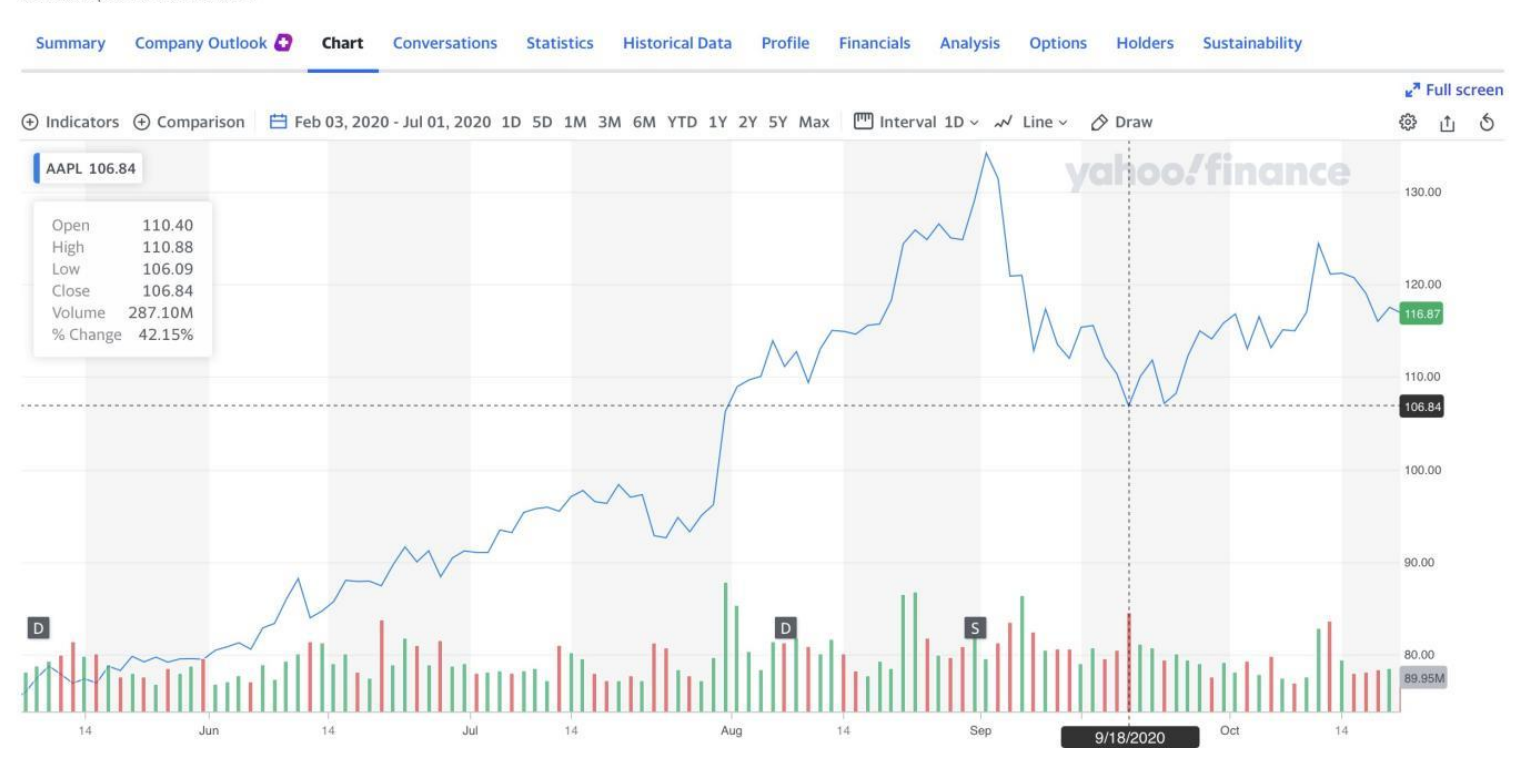

Figure 2. Apple's stock price

The reasons which caused this drop might be a lot, the most common answer might be the delay of the announcement of new Apple Products. A numbers of people waiting on this day for a long time, because Apple supposed to announce the new products like iPhone 12, iPhone 12 Pro and iPhone 12 Pro Max, etc. Nevertheless, Apple delayed the publish of their new products until October 14, 2020. There is a small peak of rising stock price on October 12, which is two days before the publish of the new products. The increasing of Apple stock might because people putted huge expectations on these new products, and they have been waited for a long period. This motivation lead them to buy these products right away, which caused the suddenly increasing price of Apple' stock. On November 2, there is a small drop on this day. The opening price is 109.11 , and the closing price is 108.77 . On December 28, there is another increasing peak on Apple's stock. The opening price is 133.99 , and the closing price 136.69. This is also the highest price of Apple stock in 2020. After 2020, Apple's stock price will continue to increase in 2021. This study used two years of data for comparison, which means it will only use data from February 3, 2021 and before. So at the beginning of 2021, Apple's stock price ushered in its first peak. On January 26, 2021, the opening price is 143.6, and the closing price is 143.16. Later on, there is a small drop until February 3, 2021. The opening price is 135.76, and the closing price is 133.94. Comparing the data at the same day but different year on February 3 , we can see that the price of Apple's stock increased by $67.4 \%$ in one year.

\section{COMPARISON WITH MICROSOFT COMPANY}

Another very famous company which can compete with Apple is Microsoft Company. Microsoft is an American multinational technology company founded by Bill Gates and Paul Allen on April 4, 1975. The company is headquartered in Redmond, Washington (near Seattle), focusing on R\&D, manufacturing, licensing and providing a wide range of computer software services. The most famous and best-selling products are Windows operating system and Office series software. It is the world's largest computer software provider and the leader of PC (Personal Computer) software development in the world. On June 23, 2021, Microsoft's market value exceeded the $\$ 2$ trillion mark. This is the second US company to enter after Apple's breakthrough of $\$ 2$ trillion. In 2019, the market value of Microsoft reached US\$1 trillion for the first time, 33 years after the original Microsoft IPO. From 1 trillion to 2 trillion, Microsoft only took about 2 years. Comparing Microsoft and Apple, Microsoft has more patents, company environment, $R \& D$ ratio, and R\&D investment than Apple. Apple's profit, profit margin, revenue, etc. are more than that of Microsoft. This is why Apple's market value can break 2 trillion earlier than Microsoft. On the two items of profit and profit margin, Microsoft's performance is not good. After all, it is an enterprise-level market. If the profit margin is too high, customers are easy to lose.

During the epidemic, Microsoft let their employees to work at home, Its stock price has also changed more or less with the epidemic flow. In March 6, 2020 report, 
Microsoft's stock price plummeted $14.74 \%$ on Monday, the largest single-day drop since April 24, 2000. At that time, Microsoft's stock price fell by $15.6 \%$. In the past month, Microsoft's stock price has fallen by $27 \%$, and the Dow has fallen by $31 \%$ [5].

In a micro perspective, during epidemic time, Microsoft's stock start decrease since February 10, 2020. At the time when Apple had their its lowest price on March 23, Microsoft also having a bad situation, but the lowest price of Microsoft price is on March 16. The opening price on that day is 140.0 , the closing price is 135.42. Even thought the stock price of Microsoft is much higher than Apple, but their volume is quite similar, even Apple's volumes are higher than Microsoft. It is because Apple's market value is higher than Microsoft.

\section{OVERALL TREND}

For Apple, the epidemic only affected it at the beginning, but it took only four months for Apple to return to its previous normal stock price. It can be seen that the true hidden strength behind Apple can enable Apple. Recovered in such a short time. The overall situation of Apple's stock price continued to rise. It only fell sharply between February and June, when the epidemic first began, but it quickly returned to its original state. During the period from August to November, the impact of Apple's new products rose first and then fell back to normal levels. There was also a peak in early 2021, and then it returned to normal levels. The overall level of Apple's stock increased by $67.4 \%$ over the same period.

For Microsoft, his situation is actually similar to that of the same type of Apple. At the beginning of the epidemic, there was a huge decline from February to March, but it was basically fully restored to the previous level before June. Like Apple, it took just four months to solve the severe damage caused by the epidemic, which shows that Microsoft's strength cannot be underestimated. Microsoft's overall trend continues to rise. However, unlike Apple, the highest value of Apple's stock is in December, which is the end of 2020, but the highest value of Microsoft's stock is in September. After September, the stock declined slightly, but it only fell to a normal level, and then slowly climbed up.

\section{CONCLUSION}

Comparing Apple's stock price and Microsoft's stock price, we can find that Microsoft's stock price is much higher than Apple's, but when we compare their number of transactions, we find that Apple's number of transactions is many times greater than that of Microsoft. This has also led to the fact that the total trading volume of Apple stock and Microsoft stock is similar, and sometimes Apple is even higher than Microsoft.

To conclude, the pandemic did not bring an irreparable blow to Apple. Instead, it only took it four months to restore its stock to its original value, or even rise. This is enough to show that Apple's foundation is stable and there are excellent strategies to enable them to recover their losses in time when they faced strong impacts. In general, Apple's stock only declined during the most severe period of the pandemic, and remained at a stable value for the rest of the time, and there was also a phenomenon of continuous rise.

\section{REFERENCES}

[1] Yahoo is now a part of Verizon Media. (n.d.). Yahoo. Retrieved August 29, 2021, from https://finance.yahoo.com/quote/AAPL/chart?

[2] Ziemba, W. T. (2020, June 21). The COVID-19 Crash in the US Stock Market. Ziemba. https://papers.ssrn.com/sol3/papers.cfm?abstract_i $\mathrm{d}=3632410$

[3] Yan, B. (2020, March 28). Analysis of the Effect of COVID-19 on the Stock Market and Investing Strategies.

Yan. https://papers.ssrn.com/sol3/Papers.cfm?abstract_i $\mathrm{d}=3563380$

[4] Camba, J. A. C. (2020). The Effects of Restrictions in Economic Activity on the Spread of COVID-19 in the Philippines: Insights from Apple and Google Mobility Indicators -The Journal of Asian Finance, Economics and Business | Korea Science. Camba. https://www.koreascience.or.kr/article/JAKO2020 34651879125.page

[5] Shivaani, M. V. (n.d.). Comparing Apple to Amazon: Just a Matter of Words in Machine Learning World | Journal of Emerging Technologies in Accounting. Shivaani. Retrieved August 29, 2021, from https://meridian.allenpress.com/jeta/articleabstract/doi/10.2308/JETA-2020045/464597/Comparing-Apple-to-Amazon-Just-aMatter-of-Words

[6] Apple (AAPL) Vs Microsoft (MSFT): Which Is A Better Tech Stock To Buy Right Now?, 28 Jan. 2021, www.nasdaq.com/articles/apple-aapl-vsmicrosoft-msft $\% 3 \mathrm{~A}$-which-is-a-better-tech-stockto-buy-right-now-2021-01-28.

[7] Osipovich Alexander. "Apple's market capitalisation has fallen below trillion, and Microsoft is the only remaining U.S. company in the trillion-dollar club." Wall Street News, 24 Mar. 2020, cn.wsj.com/articles/ 